\title{
Functional Linguistics - a new journal for the scientific study of language
}

\author{
Chenguang Chang ${ }^{*}$ and Guowen Huang
}

\author{
* Correspondence: \\ flsccg@mail.sysu.edu.cn \\ School of Foreign Languages, Sun \\ Yat-sen University, Guangzhou \\ 510275, China
}

Welcome to Functional Linguistics, a peer-reviewed open-access journal supported by the M.A.K. Halliday Library, Sun Yat-sen University, China and published by SpringerOpen. This open-access journal publishes scholarly articles and reviews in the broad area of functional linguistics, with a special focus on Systemic Functional Linguistics (SFL). Our aim is to provide a platform for the exploration of language and linguistic issues from a functional and meaning-oriented perspective.

SFL is a functional model of language inspired by the work of linguists such as Saussure, Hjelmslev, Whorf, and Firth. The theory, as a general linguistics model of language, was initially developed by M.A.K. Halliday and his colleagues in London during the 1960s, and its development has been "one of continuous expansion of its 'territory' in terms of theory, description, application, interdisciplinary engagement, and so on" (Matthiessen 2010). As the name indicates, SFL distinguishes itself as a functional theory by the emphasis placed on system in relation to structure. Martin (1984) explains that "it is... the use of paradigmatically based metafunctional components in the grammar which most clearly distinguishes systemic from other functionalist approaches". The theory has also been particularly concerned with modelling language in context. It is especially well-known for the work on discourse analysis, cohesion, genre and register, appraisal and so on, which have been taken up by scholars working in the humanities and social sciences.

Since Halliday's early work on Chinese and English, systemic functional linguists have also been increasing the coverage of the description of different languages over the decades, including French, Spanish, Portuguese, German, Danish, Finnish, Persian, Thai, Vietnamese, Japanese, Korean, Tagalog and Bahasa Indonesian.

SFL can be characterized as an "appliable" linguistics theory. Halliday (2008: 189) states that his aim is to work towards "a coherent account of language which is 'appliable', in the sense that it can be helpful to at least some of the large numbers of people who are in some way or other engaging with language in the course of their work". SFL is wellknown for its application in a variety of fields, including education, translation, computational linguistics, multimodal studies, and healthcare, and scholars are always exploring new areas of application (Matthiessen 2010).

As Fawcett (2013) points out, the development of SFL has benefited from the social structures that have been developed to maintain and nourish the theory. These include SFL associations and conferences (international, regional and national), teaching and research posts, MA and $\mathrm{PhD}$ courses and programs in universities, and

(c) 2014 Chang and Huang; licensee Springer. This is an Open Access article distributed under the terms of the Creative Commons Attribution License (http://creativecommons.org/licenses/by/4.0), which permits unrestricted use, distribution, and reproduction in any medium, provided the original work is properly credited. 
friendly publishers and journals. Since 1974, the "systemic workshop" that was originally started in Britain has grown into the International Systemic Functional Congress, which is held every year in different continents. In addition, annual regional and national conferences are held in Australia, Europe, China, Japan, Latin America and elsewhere, most often organized by regional or national associations. Functional linguistics research centres have been set up around the world, and in China, for example, these include The Halliday Centre for Intelligent Applications of Language Studies at City University of Hong Kong, The Functional Linguistics Institute at Sun Yat-sen University, The Centre for Functional Linguistics at Beijing Normal University, and The Centre for Functional Linguistics at University of Science and Technology Beijing. As we write, another centre, the Martin Centre for Appliable Linguistics, is planning its launch at Shanghai Jiao Tong University. The M. A. K. Halliday Library was formally launched at Sun Yat-sen University in 2013. The Library generously sponsors the publication of this journal, which is another attempt to establish the "infrastructure", as Fawcett (2013) uses the term, to serve the functional linguistics community.

As an international peer-reviewed open-access journal, Functional Linguistics welcomes research articles from scholars and researchers from all over the world. The journal seeks clearly written articles to promote insightful understanding and exploration of language from a functional and meaning-oriented perspective. The areas to be covered in this journal include language and context, functional grammar, semantic variation, discourse analysis, multimodality, register and genre analysis, educational linguistics, and any other relevant research field. Papers for publication in Functional Linguistics are selected through a peer review process to ensure soundness, originality, relevance, and readability. The journal adopts a rigorous peer review process to ensure independent assessment of the papers. Each paper is reviewed at least by two referees. Manuscripts that are not within the scope of the journal may be returned to the authors without a formal review. The editorial board of Functional Linguistics is composed, in addition to the editors-in-chief, of many internationally renowned linguists who help guarantee the high quality of the papers published.

Functional Linguistics publishes the following types of papers: research articles, book reviews, commentaries, reviews and short reports. Instructions for authors can be found on the journal website (http://www.functionallinguistics.com/authors/instructions).

The advantages of publishing with an Open Access journal like ours are:

- rigorous peer and editorial review;

- quick publication after acceptance;

- large dissemination and greatest possible visibility;

- increased probability of prompt citations.

As editors-in-chief, we hope you will enjoy this new journal, and we look forward to reading your contributions.

Received: 27 February 2014 Accepted: 27 February 2014 Published: 10 April 2014 
References

Fawcett, RP. 2013. Forty years back, forty years forward: a brief history of the major concepts and the social structures of Systemic Functional Linguistics with a look ahead to the future. Plenary presentation at the $40^{\text {th }}$ International Systemic Functional Congress (15-19 July, 2013). Guangzhou: Sun Yat-sen University.

Halliday, MAK. 2008. Complementarities in Language. Beijing: The Commercial Press.

Martin, JR. 1984. Functional components in a grammar: a review of deployable recognition criteria. Nottingham Linguistic Circular 13:35-70.

Matthiessen, CMIM. 2010. Systemic functional linguistics developing. Annual Review of Functional Linguistics 2:8-63.

doi:10.1186/2196-419X-1-1

Cite this article as: Chang and Huang: Functional Linguistics - a new journal for the scientific study of language. Functional Linguistics 2014 1:1.

Submit your manuscript to a SpringerOpen ${ }^{\circ}$ journal and benefit from:

- Convenient online submission

- Rigorous peer review

- Immediate publication on acceptance

- Open access: articles freely available online

- High visibility within the field

- Retaining the copyright to your article 